\title{
Gastrointestinal nematodes of goats: host-parasite relationship differences in breeds at summer mountain pasture in northern Italy
}

\author{
Sergio Aurelio Zanzani ${ }^{1}$, Alessia Libera Gazzonis ${ }^{1}$, Emanuela Olivieri ${ }^{2}$, \\ Luca Villa $^{1}$, Cristina Fraquelli ${ }^{3}$, Maria Teresa Manfredi ${ }^{1}$ \\ ${ }^{1}$ Department of Veterinary Medicine, Università degli Studi di Milano, 20133 Milan, Italy \\ ${ }^{2}$ Department of Biology and Biotechnology "Lazzaro Spallanzani”, \\ Università degli Studi di Pavia, 27100 Pavia, Italy \\ ${ }^{3}$ Studio Associato AlpVet, 21052 Busto Arsizio, Italy \\ sergio.zanzani@unimi.it
}

Received: April 16, 2019 Accepted: November 29, 2019

\begin{abstract}
Introduction: The Orobic goat is a hardy breed native to the Orobic Alps (Lombardy, northern Italy). The aim of the study was the assessment of gastrointestinal nematode (GIN) egg excretion in Alpine and Saanen (cosmopolite breeds) and Orobic grazing goats, after a strategic treatment with eprinomectin in late June. Material and Methods: Individual faecal samples from a mixed flock of cosmopolite and Orobic goats were collected and analysed by the FLOTAC double technique every three weeks from June to September. Results: Strongylida was the primary GIN infection observed in goats that grazed on Alpine pastures; a strategic treatment with eprinomectin led to a prolonged reduction of egg excretion during the whole study period. Egg excretion was also influenced by breed. Pluriparous Orobic does were able to control reinfection better than the pluriparous cosmopolite does. Regarding Nematodirus sp. eggs per gram of faeces (EPG), the autochthonous Orobic breed presented higher values than the cosmopolite breeds. However, cosmopolite goats presented higher EPG values of Strongyloides papillosus than their Orobic counterparts in August. Conclusions: Further studies on genetic features of local autochthonous goats, such as the Orobic breed, are needed, since they could reveal peculiar characteristics of susceptibility, resistance or resilience to GIN infection, providing genetic resources for selection.
\end{abstract}

Keywords: goat, breed, gastrointestinal nematodes, resistance, Italy.

\section{Introduction}

Dairy goats are reared worldwide under a wide variety of management systems, ranging from intensive to extensive. In northern Italy and mainly in the preAlpine and Alpine environments, semi-extensive and extensive breeding systems are practiced; in this context, parasitic diseases represent an ineliminable sanitary risk, in some cases linked to sympatric wild animals $(1,28)$. Protozoa and helminths infecting goats can impair production, inflict economic losses and, in some cases, cause zoonotic diseases $(14,15,27,34)$. Gastrointestinal nematodes (GIN) are the most common parasites of goats in northern Italy (11), and an integrated approach should be adopted to their control. Regular deworming effectively controls internal parasites in grazing dairy goats, but it should be properly carried out to prevent or slow down the onset of anthelmintic resistance, which has already been reported in northern Italy and neighbouring regions $(30,35,36,38)$. In this regard, in recent years strategic or targeted selective treatments have been suggested and other strategies have been developed to improve the management of gastrointestinal parasites in goats, such as nutritional supplementation with minerals, vitamins, condensed tannins, spores of Duddingtonia flagrans, and copper oxide wire particles $(13,20,25,29)$. Also, selection of animals with greater resistance or resilience to GIN enhances productivity under conditions of risk of infection by parasites and, as this leads to less frequent treatments, reduces selection pressure for anthelmintic resistance (26). Information on the potential for selecting resistant goats is very limited (21); however, genetic resources for selection of resistance or resilience against nematodes in goats could also be provided by autochthonous or local breeds $(3,6,17)$. 
Considering the lack of information on GIN dynamics in autochthonous goat breeds after treatment on Alpine ecosystem pastures, three aims seemed appropriate, and three were served by the present study. The first was to evaluate the quali-quantitative variations of GIN egg excretion due to reinfection in a naturally infected flock of dairy goats after an anthelmintic treatment, the research being intended to use the whole grazing season on a mountain pasture. The second was to investigate the influence of selected risk factors (sampling, breed, and number of births) on the faecal egg count, and the third was to find the differences in GIN reinfection between autochthonous and cosmopolite goats.

\section{Material and Methods}

The study was conducted in a flock composed of 55 lactating goats, of which 38 were pluriparous and the remaining 17 primiparous. The breed composition of the flock was 39 autochthonous (Orobic) and 16 cosmopolite (8 Alpine and 8 Saanen) animals. All were individually identified by ear tags, and the two groups of goats used the same pasture throughout the study.

The Orobic goat, a native breed of the Orobic Alps, can be found in the lower part of the Valtellina (Sondrio province), and in the provinces of Bergamo and Lecco (Lombardy, northern Italy). This goat has impressive horns and a long-haired coat in varying colours (grey, beige, black, brown, or dappled) (Fig. 1). The most common combination is black-grey in the hindquarters with a white-beige front. This hardy breed, suitable for mountain pastures, is a good source of meat and milk of high quality used for the production of traditional "violino" raw ham and raw-milk cheeses.

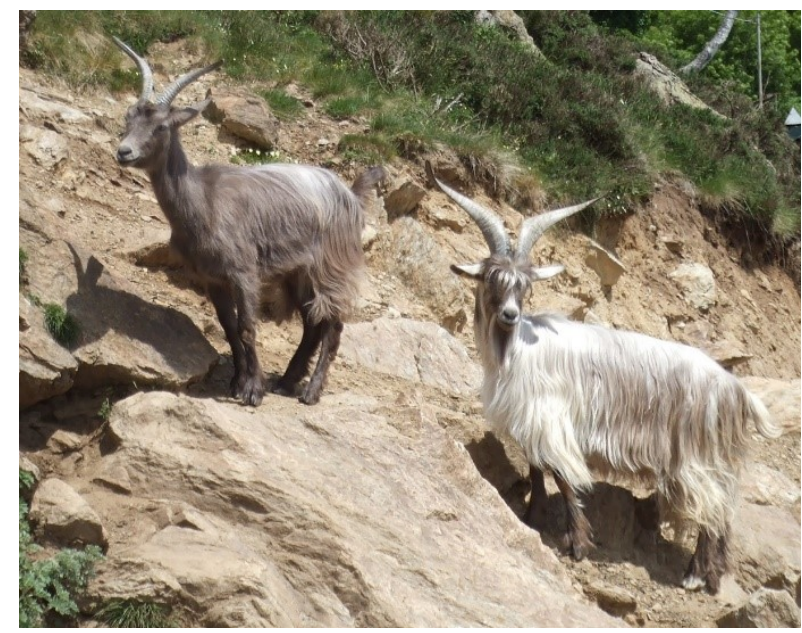

Fig. 1. Two Orobic goats in a pre-Alpine environment

The surveyed flock grazed freely from April to October on a mountain pasture (Alpe Giumello, Lombard Prealps, Lecco province, northern Italy) at an altitude of $\pm 1,600 \mathrm{~m}$ above sea level. At the end of June 2014 , the flock was treated with a pour-on formulation of eprinomectin (EPRINEX Pour-on, Merial Italia S.p.A., Italy); extra-label dose of $1 \mathrm{mg} / \mathrm{kg}$ b.w.). The body weight of the visually heaviest goat of the flock was estimated to determine the anthelmintic dose. Individual faecal samples were collected from the rectum on the day of treatment but before it (June sampling) and subsequently four times every three weeks (July, Aug1, Aug2, and Sept samplings). In previous years to the study, treatments against GIN had been given once annually and were fenbendazole $(2.5 \%$ PANACUR, MSD Animal Health S.r.l., Italy), in November or December depending on the dry status of does. All animal procedures used in this study were approved by the Milan University Institutional Animal Care and Use Committee.

Faecal samples were refrigerated and analysed within $48 \mathrm{~h}$ by the FLOTAC double technique, with an analytic sensitivity of two eggs per gram (EPG) of faeces (8). Analyses were performed using the FS2 flotation solution ( $\mathrm{NaCl}$, specific gravity 1,200). The eggs and oocysts per gram of faeces were not calculated for Skrjabinema, the cestode Moniezia, or Eimeria sp. At each sampling, eleven faecal pools consisting of five individual samples each were analysed by sedimentation and the Baermann technique to determine the presence of the first-stage larvae of lungworm and trematode eggs.

To analyse the selected risk factors, individual EPG values were introduced in generalised linear mixed models (GLMMs) as the dependent variables. The sampling (June, July, Aug1, Aug2 or Sept), the breed (Orobic or cosmopolite) and the number of births (primiparous or pluriparous) were introduced into the models as categorical independent variables. To have a larger group, Alpine and Saanen goats, both highly selected for milk production, were considered together in statistical analysis. The identity of each goat was included as a random intercept effect. The interactions between the introduced independent variables and all their possible combinations were also considered, and the models that better explained EPG excretions were chosen by Akaike's information criterion (AIC). Statistical analyses were performed using SPSS version 20.0 (IBM, USA).

\section{Results}

At the beginning of the study (the June sampling), strongylida were detected in $100 \%$ of goats $(n=55)$, and mean egg excretion was 1,498.87 EPG (standard deviation (SD) 1,925.3). Nematodirus sp. and Strongyloides papillosus - infected goats made up 54\% and $34 \%$, respectively, and their mean excretions were 5 EPG (SD 6.31) and 11.09 EPG (SD 25.7), respectively. Skrjabinema sp. (18\%), Moniezia benedeni (28\%), and Eimeria sp. (100\%) were also detected. No lungworm first-stage larvae or trematode eggs were found. Differences in EPG counts between the two goat breeds 
were observed, particularly for strongylida: the cosmopolite goats showed EPG counts from 2.1 to 3.9 times higher than Orobic goats comparing the same sampling. Also, Orobic goats presented higher Nematodirus sp. EPG than cosmopolite ones (Table 1). The mean EPG of strongylida, Nematodirus sp., and S. papillosus observed in the four subsequent samplings (July, Aug1, Aug2, and Sept) showed different trends.

A GLMM that better explained the strongylida EPG was constructed introducing all three categorical variables (sampling, breed, and number of births) and their interaction, because all the other possible combinations of independent variables and their interactions were less able to explain the strongylida egg excretion, as demonstrated by the higher AIC values (Supplementary Table 1). Considering the Nematodirus sp. EPG, the smallest AIC value was obtained by constructing a GLMM with all three categorical variables and the interaction between the breed and the number of births. In the model that better explained the EPG of S. papillosus, only the sampling, the breed and their interactions were introduced as independent variables (Supplementary Table 1). The sampling was the variable that better explained the variation of the strongylida EPG (Table 1). Pairwise comparisons showed that the estimated strongylida EPG of the June sampling was significantly higher $(p<0.001)$ than all the other samplings (Fig. 2). Strongylida EPG was also explained by the interaction between sampling, breed, and number of births. Both Orobic and cosmopolite pluriparous goats presented a higher strongylida EPG count than their primiparous flockmates in the June sampling when no animals had been treated yet with anthelmintic drugs. In the subsequent four samplings, the strongylida EPG differed between Orobic and cosmopolite goats. In Orobic goats, reinfection after treatment led to a higher strongylida EPG count in primiparous than pluriparous animals, while the opposite trend emerged in cosmopolite goats (Fig. 3).

Also for the Nematodirus sp. EPG, the sampling was the variable that better explained its variation (Table 2). Pairwise comparisons of the estimated Nematodirus sp. EPG of the June sampling with other samplings showed that its June value was significantly higher than that of the July sampling ( $p<0.001)$. In contrast, the June EPG did not differ from the Aug1 EPG $(p>0.05)$ and was significantly lower than the Aug2 and Sept counts ( $p<0.001$; Fig. 4). Also, Orobic goats presented higher Nematodirus sp. EPG than cosmopolite ones (Fig. 5). The sampling and the interaction between sampling and breed were the significant explanatory variables of the $S$. papillosus EPG. Pairwise comparisons showed that the $S$. papillosus EPG of the June and July samplings did not differ. The EPG of the Aug1 and Aug2 samplings were significantly higher than those of June ( $p<0.01$ and $<0.001$, respectively), while the latter and the Sept sampling EPG did not differ from each other (Fig. 6). June, July, and Sept sampling EPG values followed the same trend in Orobic and cosmopolite goats, while higher EPG were observed in the Aug1 and Aug2 samplings of cosmopolite goats (Fig. 7).

Table 1. Mean EPG of strongylida, Nematodirus sp., and S. papillosus. in Orobic and cosmopolite (Alpine and Saanen) goats at each sampling point

\begin{tabular}{|c|c|c|c|c|}
\hline Sampling & Breed & $\begin{array}{l}\text { Strongylida mean EPG } \\
( \pm \mathrm{SD})\end{array}$ & $\begin{array}{l}\text { Nematodirus sp. mean EPG } \\
( \pm \mathrm{SD})\end{array}$ & $\begin{array}{c}\text { S. papillosus mean EPG } \\
( \pm \mathrm{SD})\end{array}$ \\
\hline \multirow{2}{*}{ June } & Orobic & $\begin{array}{c}1228.4 \\
( \pm 988.8)\end{array}$ & $\begin{array}{c}5.8 \\
( \pm 6.6)\end{array}$ & $\begin{array}{c}11.4 \\
( \pm 27.4)\end{array}$ \\
\hline & Cosmopolite & $\begin{array}{c}2614.75 \\
( \pm 4197.2)\end{array}$ & $\begin{array}{c}1.5 \\
( \pm 2.9)\end{array}$ & $\begin{array}{c}7.0 \\
( \pm 15.5)\end{array}$ \\
\hline \multirow{2}{*}{ July } & Orobic & $\begin{array}{c}35.1 \\
( \pm 47.4)\end{array}$ & $\begin{array}{c}2.1 \\
( \pm 6.0)\end{array}$ & $\begin{array}{c}12.9 \\
( \pm 31.1)\end{array}$ \\
\hline & Cosmopolite & $\begin{array}{c}124.5 \\
( \pm 206.3)\end{array}$ & $\begin{array}{c}0.3 \\
( \pm 0.7)\end{array}$ & $\begin{array}{c}11.5 \\
( \pm 20.6)\end{array}$ \\
\hline \multirow{2}{*}{ August 1} & Orobic & $\begin{array}{c}170.2 \\
( \pm 121.8)\end{array}$ & $\begin{array}{c}8.2 \\
( \pm 11.9)\end{array}$ & $\begin{array}{c}11.7 \\
( \pm 27.7)\end{array}$ \\
\hline & Cosmopolite & $\begin{array}{c}354.5 \\
( \pm 371.4)\end{array}$ & $\begin{array}{c}2.5 \\
( \pm 2.1)\end{array}$ & $\begin{array}{c}57.0 \\
( \pm 140.9)\end{array}$ \\
\hline \multirow{2}{*}{ August 2} & Orobic & $\begin{array}{c}67.2 \\
( \pm 63.5)\end{array}$ & $\begin{array}{c}17.2 \\
( \pm 16.3)\end{array}$ & $\begin{array}{c}10.6 \\
( \pm 21.1)\end{array}$ \\
\hline & Cosmopolite & $\begin{array}{c}265.6 \\
( \pm 432.84)\end{array}$ & $\begin{array}{c}4.0 \\
( \pm 4.9)\end{array}$ & $\begin{array}{c}110.4 \\
( \pm 193.5)\end{array}$ \\
\hline \multirow[b]{2}{*}{ September } & Orobic & $\begin{array}{c}52.2 \\
( \pm 63.2)\end{array}$ & $\begin{array}{c}17.4 \\
( \pm 22.8)\end{array}$ & $\begin{array}{c}4.11 \\
( \pm 6.9)\end{array}$ \\
\hline & Cosmopolite & $\begin{array}{c}159.11 \\
( \pm 228.1)\end{array}$ & $\begin{array}{c}9.8 \\
( \pm 6.0)\end{array}$ & $\begin{array}{c}5.3 \\
( \pm 11.3) \\
\end{array}$ \\
\hline
\end{tabular}




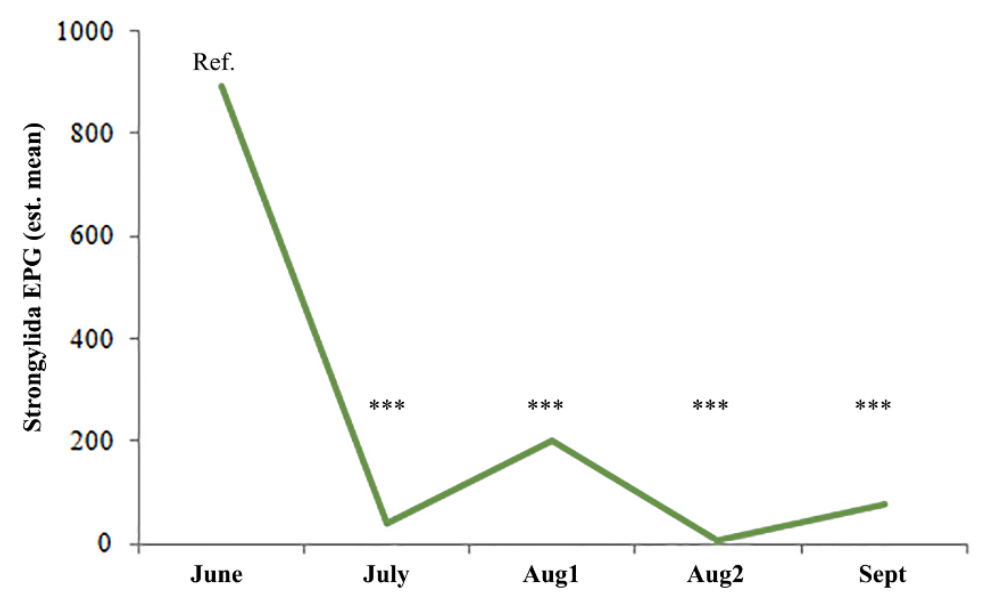

Fig. 2. Effect of sampling on strongylida EPG in both autochthonous and cosmopolite goats at summer mountain pasture in northern Italy
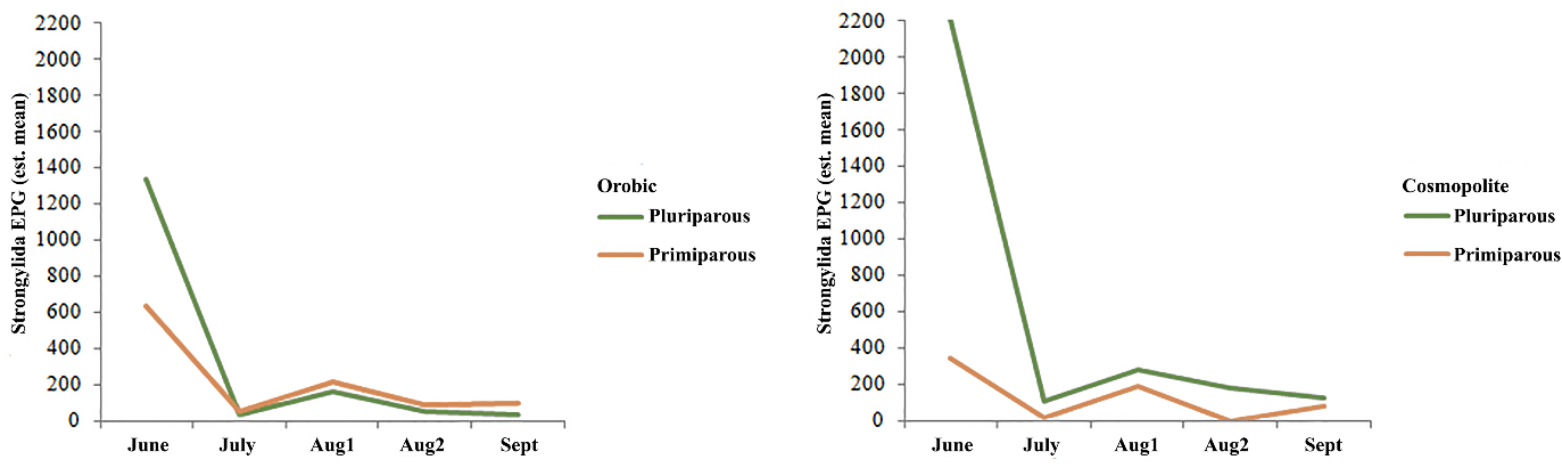

Fig. 3. Influence of sampling, births, and breed on strongylida EPG in goats at summer mountain pasture in northern Italy

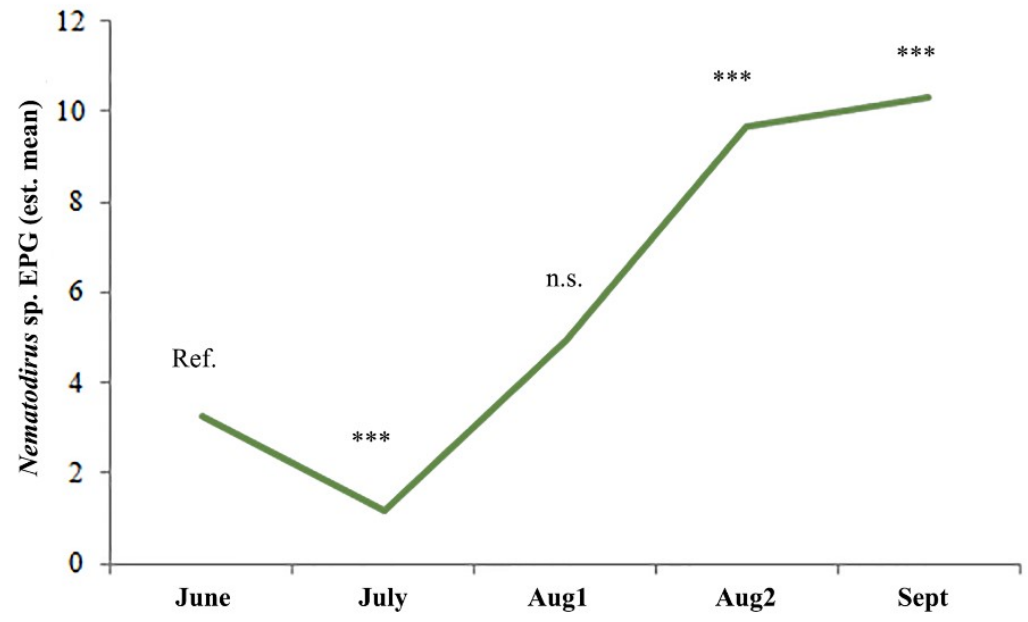

Fig. 4. Effect of sampling on Nematodirus sp. EPG in goats at summer mountain pasture in northern Italy Ref - reference; ${ }^{* * *}-\mathrm{P}<0.001$; n.s. - not significant 


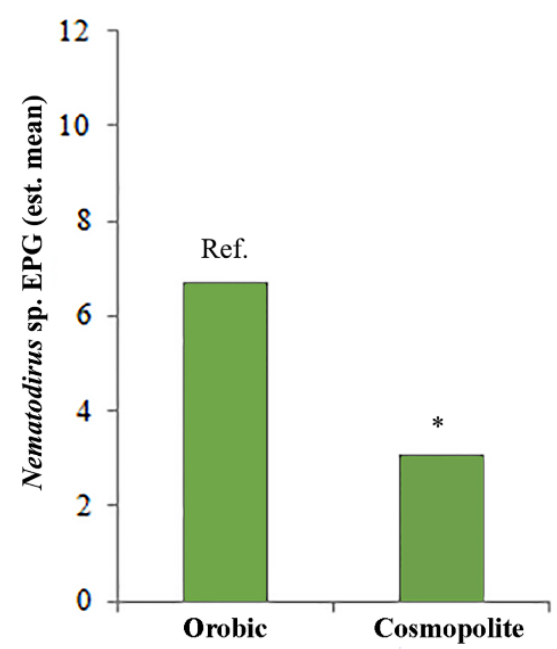

Fig. 5. Effect of breed on Nematodirus sp. EPG in goats at summer mountain pasture in northern Italy Ref. - reference; ${ }^{*}-\mathrm{P}<0.05$

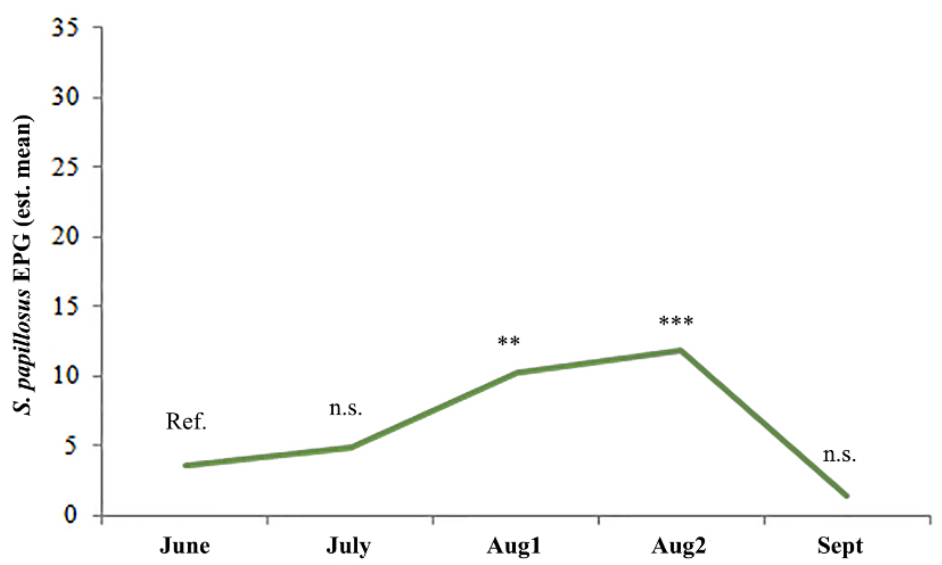

Fig. 6. Effect of sampling on Strongyloides papillosus EPG in goats at summer mountain pasture in northern Italy

Ref. - reference; ** $\mathrm{P}<0.01$; *** $-\mathrm{P}<0.001$; n.s. - not significant

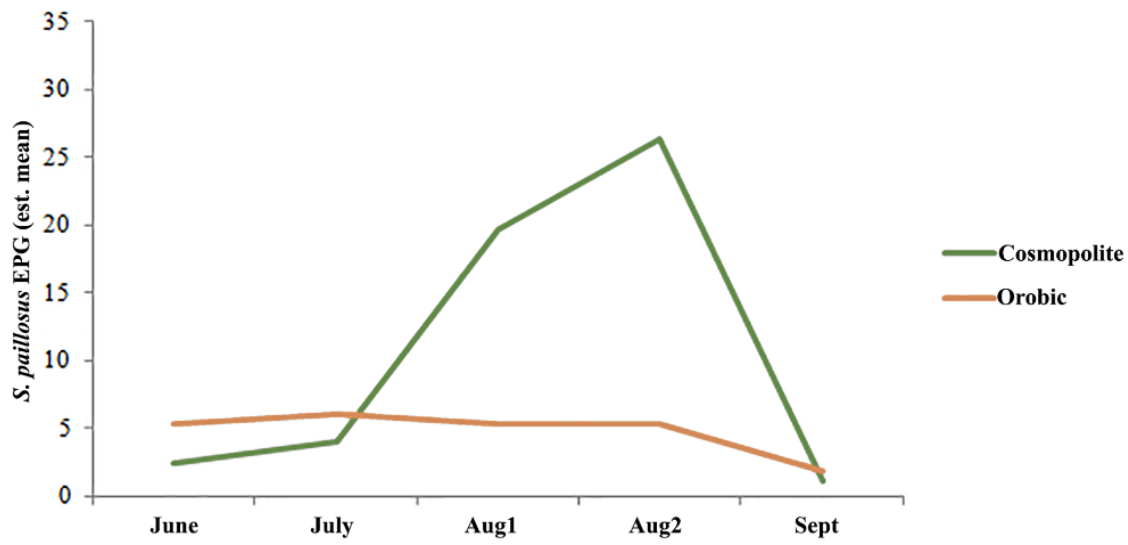

Fig. 7. Effect of sampling and breed on S. papillosus EPG in goats at summer mountain pasture in northern Italy

\section{Discussion}

Strongylida infection was the main parasitic infection observed in untreated goats that freely grazed on mountain pastures, and this finding was in accordance with previous parasitological surveys in goats from northern Italy $(11,28)$; indeed, $100 \%$ of surveyed animals were infected at the beginning of the study, and high EPG values were found (mean EPG 1,498.87). The decrease in strongylida EPG recorded in the samplings subsequent to June was probably caused by the anthelmintic treatment. In particular, the lower 
egg excretion observed in the July sampling, three weeks after treatment, was probably due to the immediate efficacy of the administered drug (9), whereas the prolonged lower excretion in the following samplings could also be due to other factors. Firstly, pour-on eprinomectin is known for its persistent efficacy, mainly in cattle $(7,12)$. Probably, as observed by Chartier and Pors (5), its persistence is shorter in goats, although pour-on eprinomectin at a dose of $1 \mathrm{mg} / \mathrm{kg} \mathrm{b}$.w. has been demonstrated to completely prevent Teladorsagia circumcincta and Trichostrongylus colubriformis infections 7 days after administration and partially protect against $T$. circumcincta reinfection 21 days after. As observed by Genchi (16), a strategic anthelmintic treatment in late spring leads to lower contamination of pastures than treatments administered in early spring. As a consequence, a strategic prophylactic treatment in May or June, during the goat lactating period, has been observed to dramatically improve productivity in small ruminants $(10,33,36)$. Some contribution to the observed persistent lower egg excretion by acquired immunity is possible but somewhat unlikely: in goats, constantly increasing egg excretion has been observed over the whole grazing season, probably because both the acquisition and the expression of immune responses against GIN are less efficient than in sheep (24). Moreover, goats seem to be unable to develop a response to nematode parasites after challenge infection (22).

Considering Nematodirus sp. infection, the EPG varied depending on samplings. As was also the case for strongylida, the EPG registered in the July sampling was significantly lower than that in its June antecedent, likely owing to the immediate efficacy of eprinomectin against Nematodirus sp. $(18,19)$. In the subsequent samplings, the egg excretion trend differed from that observed for strongylida; although the Nematodirus sp. EPG fell in July, it progressively rose to its maximum at the Sept sampling when it surpassed its pre-treatment level. During reinfection after treatment with macrocyclic lactones, differences between Nematodirus sp. and strongylida excretion were previously observed in cattle (31). In some studies, species belonging to the Nematodirus genus appeared to be dose-limiting for these drugs $(4,37)$; therefore, eprinomectin in goat at the dose used probably lacked persistent efficacy against the species belonging to this genus.

Finally, the trend of EPG of S. papillosus seemed utterly unaffected by anthelmintic treatment throughout the sampling period. This result was not unexpected because eprinomectin is not registered as effective against S. papillosus, and Hamel et al. (19) observed an efficacy of $<90 \%$ in goats treated with a dose of $1 \mathrm{mg} / \mathrm{kg} \mathrm{b}$.w. The rise in S. papillosus EPG in the August sampling was not definitively explainable, but possibly a substantial decrease in other GIN due to eprinomectin treatment could have reduced competition in its ecological niche. Also, other factors could have influenced excretion of S. papillosus in the study period, such as environmental and meteorological variables and reinfections.
Differences in the EPG of detected nematodes varied by other risk factors. At the beginning of the study period, the strongylida EPG was higher in pluriparous goats of both Orobic and cosmopolite breeds than primiparous. After anthelmintic treatment and the consequent reinfection, in contrast, the EPG differed in primiparous and pluriparous goats by breed. In cosmopolite goats, the strongylida EPG was characterised by higher values in pluriparous than in primiparous animals; according to Hoste et al. (23), this phenomenon is very likely to be a consequence of the low ability of goats to produce effective immunity against GIN. An opposite trend of reinfection was observed in Orobic goats, with higher EPG in primiparous than pluriparous individuals, possibly related to acquired immunity being stronger in the autochthonous than the cosmopolite breeds. Recently, low heritability of faecal egg counts was observed in the cosmopolite breeds (Alpine and Saanen), together with an unfavourable genetic correlation of faecal egg counts with milk yield (21). Heritability and genetic correlation could vary in autochthonous breeds. Indeed, GIN affected milk production in Nera di Verzasca goats (a local Italian breed) differently to cosmopolite breeds $(2,3)$, suggesting that autochthonous breeds could provide genetic resources for heritable resistance or resilience against strongylida.

The goat breed variable accounted for Nematodirus sp. EPG in that the autochthonous Orobic breed manifested higher EPG than cosmopolite goats. The Orobic goats have probably been selected locally in the Alpine and pre-Alpine environment for capacity to sustain the host-parasite relationship in the presence of abundant infective stages of Nematodirus sp. on pastures.

Finally, cosmopolite goats presented higher EPG values of $S$. papillosus than Orobic goats in August; it can be hypothesised that the Orobic variety become more resistant or resilient to $S$. papillosus infection when other GIN infections decrease. However, our attempt to explain the observed effect of goat breed on Nematodirus sp. and S. papillosus EPG counts can only be speculative, also for the lack of previous studies. Further investigations should be performed to verify these hypotheses.

In conclusion, acknowledging strongylida to be one of the major constraints on the productivity and health of grazing ruminants, the results of the present study showed that a strategic treatment in grazing lactating goats led to a prolonged effect on the strongylida EPG of excretion and thus contributed to efficient integrated control of GIN infection. It should also be considered that the use of a drug registered at a specific dose for goats and without a milk withdrawal period, such as eprinomectin, could support the farming of both cosmopolite and autochthonous breeds on marginal mountain pastures. Further studies on the genetic features of local autochthonous goat breeds, such as the Orobic, are needed, since they could present peculiar 
features of susceptibility, resistance or resilience to GIN infection, providing genetic resources for selection.

Conflict of Interests Statement: The authors declare that there is no conflict of interests regarding the publication of this article.

Financial Disclosure Statement: This study received no funding.

Animal Rights Statement: The experiments on animals were conducted in accordance with the local Ethical Committee laws and regulations as regards care and use of experimental animals.

Supplementary Table 1 comprises a separate pdf file viewable online at http://content.sciendo.com/view/ journals/jvetres/jvetres-overview.xml and doi: 10.2478/ jvetres-2019-0076

\section{References}

1. Alberti E.G., Gioia G., Sironi G., Zanzani S.A., Riccaboni P., Magrini M., Manfredi M.T.: Elaphostrongylus cervi in a population of red deer (Cervus elaphus) and evidence of cerebrospinal nematodiasis in small ruminants in the province of Varese, Italy. J Helminthol 2011, 85, 313-318.

2. Alberti E.G., Zanzani S.A., Ferrari N., Bruni G., Manfredi M.T.: Effects of gastrointestinal nematodes on milk productivity in three dairy goat breeds. Small Rum Res 2012, 106 (Suppl.), 12-17.

3. Alberti E.G., Zanzani S.A., Gazzonis A.L., Zanatta G., Bruni G., Villa M., Rizzi R., Manfredi M.T.: Effects of gastrointestinal infections caused by nematodes on milk production in goats in a mountain ecosystem: Comparison between a cosmopolite and a local breed. Small Rum Res 2014, 120, 155-163.

4. Borgsteede F.H.M., Taylor S.M., Gaasenbeek C.P.H., Couper A., Cromie L.: The efficacy of an ivermectin/closantel injection against experimentally induced infections and field infections with gastrointestinal nematodes and liver fluke in cattle. Vet Parasitol 2008, 155, 235-241.

5. Chartier C., Pors I.: Duration of activity of topical eprinomectin against experimental infections with Teladorsagia circumcincta and Trichostrongylus colubriformis in goats. Vet Parasitol 2004, $125,415-419$.

6. Chiejina S.N., Behnke J.M., Fakae B.B.: Haemonchotolerance in West African Dwarf goats: Contribution to sustainable, anthelmintics-free helminth control in traditionally managed Nigerian dwarf goats. Parasite 2015, 22, 7.

7. Cramer L.G., Pitt S.R., Rehbein S., Gogolewski R.P., Kunkle B.N., Langholff W.K., Bond K.G., Maciel A.E.: Persistent efficacy of topical eprinomectin against nematode parasites in cattle. Parasitol Res 2000, 86, 944-946.

8. Cringoli G., Rinaldi L., Maurelli M.P., Utzinger J.: FLOTAC: New multivalent techniques for qualitative and quantitative copromicroscopic diagnosis of parasites in animals and humans. Nat Protoc 2010, 5, 503-515.

9. Cringoli G., Rinaldi L., Veneziano V., Capelli G., Rubino R.: Effectiveness of eprinomectin pour-on against gastrointestinal nematodes of naturally infected goats. Small Rum Res 2004, 55, 209-213.

10. Cringoli G., Veneziano V., Jackson F., Vercruysse J., Greer A.W., Fedele V., Mezzino L., Rinaldi L.: Effects of strategic anthelmintic treatments on the milk production of dairy sheep naturally infected by gastrointestinal strongyles. Vet Parasitol 2008, 156, 340-345.
11. Di Cerbo A.R., Manfredi M.T., Zanzani S.A., Stradiotto K.: Gastrointestinal infection in goat farms in Lombardy (Northern Italy): Analysis on community and spatial distribution of parasites. Small Rum Res 2010, 88, 102-112.

12. Dorny P., Demeulenaere D., Smets K., Claerebout E., Vercruysse J.: Persistent efficacy of topical doramectin and eprinomectin against Ostertagia ostertagi and Cooperia oncophora infections in cattle. Vet Rec 2000, 147, 139-140.

13. Fraquelli C., Zanzani S.A., Gazzonis A.L., Rizzi R., Manfredi M.T.: Effects of condensed tannin on natural coccidian infection in goat kids. Small Rum Res 2015, 126, 19-24.

14. Gazzonis A.L., Alvarez Garcia G., Zanzani S.A., Ortega Mora L.M., Invernizzi A., Manfredi M.T.: Neospora caninum infection in sheep and goats from north-eastern Italy and associated risk factors. Small Rum Res 2016, 140, 7-12.

15. Gazzonis A.L., Veronesi F., Di Cerbo A.R., Zanzani S.A., Molineri G., Moretta I., Moretti A., Fioretti D.P., Invernizzi A., Manfredi M.T.: Toxoplasma gondii in small ruminants in Northern Italy - Prevalence and risk factors. Ann Agric Environ Med 2015, 2, 62-68.

16. Genchi C.: Schemi terapeutici e antielmintico-resistenza (Therapy and anthelmintic resistance - in Italian). Parassitologia 2006, 48, 423-431.

17. Gunia M., Phocas F., Gourdine J.L., Bijma P., Mandonnet N.: Simulated selection responses for breeding programs including resistance and resilience to parasites in creole goats. J Anim Sci 2013, 91, 572-581.

18. Hamel D., Bosco A., Rinaldi L., Cringoli G., Kaulfuß K.H., Kellermann M., Fischer J., Wang H., Kley K., Mayr S., Rauh R., Visser M., Wiefel T., Fankhauser B., Rehbein S.: Eprinomectin pour-on (EPRINEX ${ }^{\circledR}$ Pour-on, Merial): Efficacy against gastrointestinal and pulmonary nematodes and pharmacokinetics in sheep. BMC Vet Res 2017, 13, 148.

19. Hamel D., Visser M., Kellermann M., Kvaternick V., Rehbein S.: Anthelmintic efficacy and pharmacokinetics of pour-on eprinomectin ( $1 \mathrm{mg} / \mathrm{kg}$ body weight) against gastrointestinal and pulmonary nematode infections in goats. Small Rum Res 2015, 127, 74-79.

20. Healey K., Lawlor C., Knox M.R., Chambers M., Lamb J., Groves P.: Field evaluation of Duddingtonia flagrans IAH 1297 for the reduction of worm burden in grazing animals: Pasture larval studies in horses, cattle and goats. Vet Parasitol 2018, 258, 124-132.

21. Heckendorn F., Bieber A., Werne S., Saratsis A., Maurer V., Stricker C.: The genetic basis for the selection of dairy goats with enhanced resistance to gastrointestinal nematodes. Parasite 2017, 24, 2017033.

22. Hoste H., Chartier C.: Response to challenge infection with Haemonchus contortus and Trichostrongylus colubriformis in dairy goats. Consequences on milk production. Vet Parasitol 1998, 74, 43-54.

23. Hoste H., Chartier C., Le Frileux Y.: Control of gastrointestinal parasitism with nematodes in dairy goats by treating the host category at risk. Vet Res 2002, 33, 531-545.

24. Hoste H., Sotiraki S., Landau S.Y., Jackson F., Beveridge I. Goat-nematode interactions: think differently. Trends Parasitol 2010, 26, 376-381.

25. Kearney P.E., Murray P.J., Hoy J.M., Hohenhaus M., Kotze A.: The "Toolbox" of strategies for managing Haemonchus contortus in goats: What's in and what's out. Vet Parasitol 2016, 220, 93-107.

26. Leathwick D.M., Besier R.B.: The management of anthelmintic resistance in grazing ruminants in Australasia-Strategies and experiences. Vet Parasitol 2014, 204, 44-54.

27. Manfredi M.T., Di Cerbo A.R., Zanzani S.A., Moriggia A., Fattori D., Siboni A., Bonazza V., Filice C., Brunetti E.: Prevalence of echinococcosis in humans, livestock, and dogs in northern Italy. Helminthologia 2011, 48, 59-66.

28. Manfredi M.T., Di Cerbo A.R., Zanzani S.A., Stradiotto K.: Breeding management in goat farms of Lombardy, northern Italy: 
risk factors connected to gastrointestinal parasites. Small Rum Res 2010, 88, 113-118

29. Min B.R., Hart S.P.: Tannins for suppression of internal parasites J Anim Sci 2003, 81, 102-109.

30. Murri S., Knubben-Schweitzer G., Torgerson P., Hertzberg H.: Frequency of eprinomectin resistance in gastrointestinal nematodes in goats in canton Berne, Switzerland. Vet Parasitol 2014, 203, 114-119.

31. Ranjan S., Trudeau C., Prichard R.K., Daigneault J., Rew R.S.: Nematode reinfection following treatment of cattle with doramectin and ivermectin. Vet Parasitol 1997, 72, 25-31.

32. Rehbein S., Kellermann M., Wehner T.A.: Pharmacokinetics and anthelmintic efficacy of topical eprinomectin in goats prevented from grooming. Parasitol Res 2014, 113, 4039-4044.

33. Rinaldi L., Cringoli G.: Parasitological and pathophysiological methods for selective application of anthelmintic treatments in goats. Small Rum Res 2012, 103, 18-22.

34. Rinaldi L., Veneziano V., Cringoli G.: Dairy goat production and the importance of gastrointestinal strongyle parasitism. Trans R Soc Trop Med Hyg 2007, 101, 745-746.
35. Scheurle M., Mahling M., Pfister K.: Anthelminthic resistance of Haemonchus contortus in small ruminants in Switzerland and Southern Germany. Wien Klin Wochenschr Suppl 2009, 121, 46-49.

36. Veneziano V., Rubino R., Fedele V., Rinaldi L., Santaniello M. Schioppi M., Cascone C., Pizzillo M., Cringoli G.: The effects of five anthelmintic treatment regimens on milk production in goats naturally infected by gastrointestinal nematodes. S Afr J Anim Sci 2004, 34, 251-253.

37. Yazwinski T.A., Tucker C.A., Wray E., Jones L., Reynolds J., Hornsby P., Powell J.: Control trial and fecal egg count reduction test determinations of nematocidal efficacies of moxidectin and generic ivermectin in recently weaned, naturally infected calves. Vet Parasitol 2013, 195, 95-101.

38. Zanzani S.A., Gazzonis A.L., Di Cerbo A., Varady M., Manfredi M.T.: Gastrointestinal nematodes of dairy goats, antihelmintic resistance and practices of parasite control in Northern Italy. BMC Vet Res 2014, 10, 114 